\title{
Community Participation in Water Resources Management in South Africa
}

\author{
Maxwell K. Boakye and Oghenerobor B. Akpor
}

\begin{abstract}
Community participation has become widely accepted through legislation as a critical component of managing water resources in South Africa. However, achieving meaningful participation continues to be a challenge especially for the previously disadvantaged communities. The purpose of this study was to find out whether the disadvantaged community participants find their participation in Catchment Management Forum to be meaningful. A qualitative research approach that involved the use of primary and secondary data sources were used to achieve the aim of this study. Information obtained from participants were analysed thematically. The results established that, the disadvantaged communities did not find their participation to be meaningful because their expectations have not yet been met. The reliance on community organizations also excluded the majority of the population since these organizations did not interact with the community, hence not serving as intermediaries. Also, it was observed that participants did not understand the technical nature of information presented, which may be attributed to insufficient knowledge of water resource management. It is therefore important that more emphasis be placed on the development of skills and capacity of participants to understand and make meaningful contributions, especially participants from the disadvantaged communities.
\end{abstract}

Index Terms-Community participation, forum, participants, water management, water resources.

\section{INTRODUCTION}

During the past two decades, participation has been embraced in several environmental regulations relating to different sectors. The importance of public participation in environmental decision-making has been recognised at both national and international level with plethora of high-level pronouncements and public exhortations to support the involvement of affected parties in decision-making process. At international level, the United Nations Conference on Environment and Development in Rio in 1992 (UNCED or the 'Earth Summit') emphasized the need for public involvement in the design and implementation of all sorts of environmental policy. Principle 10 of the Rio Declaration on Environment upholds the idea of broad based public participation in environmental decision-making as follows: 'environmental issues are best handled with participation of all concerned citizens, at the relevant level...each individual shall have appropriate access to information concerning the environment that is held by public authorities and the opportunity to participate in decision-making process...' [1].

Manuscript received November 19, 2012; revised December 7, 2012.

M. K. Boakye is with the Department of Environmental, Water and Earth Sciences, Tshwane University of Technology, Pretoria, South Africa (e-mail BoakyeM@tut.ac.za).

O. B. Akpor is with the Institute for Economic Research on Innovation, Tshwane University of Technology, 159 Skinner Street, Pretoria, South Africa (e-mail: AkporBO@tut.ac.za).
The virtues of participatory governance needed no convincing in post-apartheid South Africa [2]. Political changes have provided the most direct impetus for policy-makers to involve citizens in decision-making process demand by anti-apartheid activist for people power. Public participation became critical to redressing the inequalities of the past by including those who were marginalized and excluded from decision-making process. The new constitutional order has provided an opening for citizen participation in decision-making affecting them. The Constitution of the Republic of South Africa (1996) requires that each sphere of government and each organ of state must apply the following principles: "people's needs must be responded to, and the public must be encouraged to participate in policy-making; and transparency must be fostered by providing the public with timely, accessible and accurate information" (Section 195(1). The need for the development of policies and frameworks that will enable communities to effectively participate in the decision-making process including environmental decision-making became urgent.

Public participation in environmental decision-making in South Africa gained a strong legal basis during the Consultative National Environmental Policy Process (CONNEPP) in 1995 which led to the adoption of the National Environmental Management Act (NEMA) in 1998. The legislation is aimed at addressing the past alienation of citizens in decision-making and gives equal rights to citizens as enshrined in the Constitution of South Africa (Act 108 of 1996).The democratization process impacted on the philosophical thinking of water management sector as well with people feeling a growing need to contribute in decision-making process due to the lack of trust and legitimacy in previous system [3], [4]. Water management institution therefore needed to be more people-oriented as opposed to the technocratic-orientation of the past. The need for people-oriented management in water management was to provide an opportunity for water management institutions to share ideas with the local community [5]- [8].

Water managers therefore needed to be able to deal with multiple stakeholder preferences in order to succeed in the implementation of water management strategies. Generally, it is agreed by the different stakeholders in water management (policy makers, researchers and water managers) that sustainable, integrated water resource management must be done at the level of the river basin or catchment [7]. Water management institutions in South Africa have therefore been re-structured to ensure the participation of the public in water resource management. The catchment management forum (CMF) in the view of [5] and is the institutional level in water resource management which provides the opportunity for citizens to express their views on water resources management. The CMF according to the South Africa 
National Water Act (NWA) of 1998 is a non-statutory water management institution which is to assist in the setting up of statutory water management institution [8]. This platform is meant to ensure that decisions-making processes are holistic, integrated and participatory in order to enjoy a wide consensus from stakeholders. Besides, management plans require public support for its successful implementation thus the active involvement of the public is needed to leverage the success of the NWA [9], [10](Republic of South Africa, 1997; 1998).Water resources management institutions such as the CMF were required by legislation to include previously disadvantaged and marginalized community groups with the aim of addressing past alienation of citizens in decision-making The National Water Act (NWA) of 1998 therefore mandates the participation of the general public, especially those from the previously disadvantaged and marginalized groups, as critical in achieving its goals in the areas of water conservation, management and monitoring which are the objectives of water management institutions. According to Du Toit [11], policies and legislation on public participation processes in South Africa are silent on how best public involvement can be achieved. Faysse [5] found that little emphasis has been placed on the capacity of participants and how they feel about the process. This study was aimed at exploring the involvement of previously disadvantaged and marginalized communities in Catchment Management Forums (MCMF) in South Africa.

\section{Study Design AND Method}

The study was conducted in the Msunduzi river catchemnet, located in the Msunduzi Municipality in the KwaZulu-Natal Province of South Africa. The catchment covers an area of 540 square kilometers, with most of the people living in the catchment coming from the previously disadvantaged and marginalized communities of South Africa and lacking understanding of environmental and development issues [12] (Rivers-Moore and Hay, 2002).

A multi research data collection method, comprising of primary (semi-structured interviews) and secondary data sources was used for the study. The secondary data sources comprised of minutes of catchment management forums, internal reports by the Department of Water Affairs (DWA), policy guidelines, and memoranda on MCMF and other published literatures.

The sampling method adopted for the study was purposeful, with only those who have attended or attending MCMF included in the study. The respondents were selected from the lists of participants who attend MCMF obtained from the DWA and then used to represent the population of eligible respondents for the study. The sample size for the study was achieved through saturation of data. A total of 19 participants, comprising of members of organizations from the disadvantaged communities, advantaged NGOs, company, municipality and DWA.

After the interviews, significant themes from the participants' statements were identified and presented in illustrative quotes and used for discussion as suggested by [13]. The themes from respondents' statements were categorized based on the questions which were designed to answer the objectives of the study. The themes from respondents were analyzed by subjectively examining the underlying trends in the themes.

\section{FINDINGS AND DISCUSSION}

\section{A. Expectation of Participants}

One of the objectives of this study was to determine the extent to which the participation process meets the expectations of participants. Historically, the DWA has had minimal relationships with the general public and its support for public participation emerged as a result of the new democratic principle in South Africa which seeks to address the past alienation of citizens in decision-making and give equal rights to citizens as enshrined in the Constitution of South Africa (Act 108 of 1996). As a public institution, DWA is legally obliged to involve the public in deliberations but the involvement of the public is voluntary without any obligation to participate on the part of the general public [6], [10]. When participants were asked on their main reason for getting involved in the MCMF, some of the responses were:

"I have realized that there is poor management of water and just wanted to take an active role because I always see big amount of water being wasted through pipe burst and nobody doing anything about it so my organization is educating the people about water management"

"My interest is about water delivery and pollution because the water is dirty and our children play there"

"Our main reason for joining the process is related to the issues of water supply and management because in our townships along the route we always see water are being wasted (through pipe burst) for no reasons"

"Our participation initially was to deal with access to water for communities as well as transfer of skills in environmental management specifically to disadvantaged communities"

There is often a considerable gap between expectations and opportunities that a participation process can provide which calls for the clarification of goals to participants about what they can achieve in the participation process [14]. Based on the legal status of water management institutions described by [6], the CMF can be classified as tokenism under Arnstein's ladder of public participation whereby the organizers are not obliged to implement the views of participants. Participants concerns that their views are not taken into consideration can be attributed to their lack of awareness that the CMF is a non-statutory or decision-making institution. According to Du Toit [11], there is a generally unrealistic expectation among participants in a public participation process in South Africa due to poor public awareness campaigns in the current democratic dispensation which has shifted all responsibilities to the government. This has therefore created the impression among citizens that their views as expressed in a public participation process should be implemented.

\section{B. Clarity of Objectives of the Process}

In a public participation process, clarity on the purpose of the process is important since it helps in dealing with the gap between the expectation of participants and the actual opportunities that the process provides [15]. Proper clarification of the objectives of the process could assist 
organizers of the process in attracting participants that have the same interest. This helps in reducing the gap between expectation and what the processes can deliver since participants become aware of both [11]. When participants were asked if the purpose of the forum was made known to them and if their purpose for joining was been met, the major responses where:

"Our objective as an organization (for participating) has not yet been met”

"I must say that my expectations for joining have not been met yet because sometimes they do what I say and sometimes not"

"So far they are not solving our problems"

All the participants from the forum could not give an indication of how the overall purpose of the forum was made known to them but are most often made aware of the purpose of each meeting. This may account to why their expectations were yet to be met. The disparity between expectations and opportunities for participating by stakeholders can be attributed to the lack of knowledge by participants about the purpose and functions of the forum [6].

\section{Technique of Information Presentation}

The choice of techniques determines the level of interaction of participants in sharing ideas in a participation process. It is also argued that the knowledge of each other's perspectives on issues of interest to stakeholders in a participation process is limited by the techniques used. These techniques are grouped into three, which are: information dispersal, information gathering and promotion of interaction [16]. When participants were asked on the technique usually used in the MCMF, some of the responses where:

"Each meeting has an agenda and you are able to submit items to the agenda before the meeting but a lot of the agenda items are reoccurring so it is a kind of interactive process and you are free to communicate with the chairperson"

"The process (MCMF) I will say is interactive because the essence of being in a forum is to interact and get access to information"

"I think the procedure used at the meetings is interaction and they do interact with us",

From the responses, it was obvious that participants were satisfied with the public participation technique used at the moment by DWA representatives who are the organizers of the forum. The technique promoted interaction between participants and organizers of the forum. It is suggested that personal interaction in a participation process helps in the enhancement of the social networking of individuals and the provision of opportunities for learning. Also, it could serve as a means of informal knowledge transfer for participants who are unable to understand some information presented at a participation process.

\section{Inclusiveness of the Process}

One objective of the NWA of 1998 is to ensure the inclusiveness of participants who have interest or have been affected by issues to be discussed. According to Khan [17], participatory democracy which strives for the involvement of all citizens is seen as the means of giving people especially those at the grassroots level a voice in decision-making in South Africa. In the view of Kessler, [18], however, participation process cannot include all citizens because it will neither be useful nor possible and can lead to alienation due to the large number of people that the process may attract which will be constrain by space, time and money. Reliance has therefore been placed on community based organizations (CBOs), environmental groups and non-governmental organizations (NGOs) in modern democracies in expressing the views of citizens, under the assumption that those channels of communication are easily accessible to citizens. These groups may also be directly or indirectly affect by issues that are been discussed and may represent a wide range of interest that individuals may not have [19]. However, accountability of these groupings has become issue in recent years with others such as Naidoo [20] argue that they do not have the mandate of the people since they do not represent any constituency but themselves. Based on this assertion, the DWA representative was asked whether they investigate these groupings about their objectives, funding as well as achievements in their own communities. The following quote is the response of the DWA representative for MCMF:

"We don't investigate the organizational structure of NGOs and CBOs and their objectives...we don't investigate their number or years of existence, their success in the community but they introduce themselves at the forum as to who they are but we don't investigate them"

The above statement indicates that these groupings are not investigated that can create an illusion that; they are interacting with the community or serving as intermediaries which in reality the organizations may exist for themselves. Participants were asked whether they interact with members of their community after meetings since most of them belonged to one or more of these groups.

"After the meeting we share it (information) in our organization but not to the whole community but I often call meeting with members of my organization and we are only eight (members of that organization)"

"After meeting (the MCMF) I call a meeting with members of my organization to inform them what we discussed (at the MCMF) but I have to give them transport which I don't have so it doesn't happen always but if I have the money I call them to tell them"

"No I used to tell (what was discussed at the MCMF) members of my organization but not the whole community"

"I am the secretary so I am the one who often attends the meeting (MCMF) and when I come back (from the MCMF) I call a meeting to tell members of my organization what was discussed...we are eight in the organization"

The above statements indicate that, NGOs and CBOs that are attending the MCMF are not serving any purpose to the communities since these organizations do not serve as intermediaries between the community and the organizers of MCMF due to their lack of interaction with members of their communities. The lack of interaction between MCMF participants and the general community makes community organizations less favorable at the moment for DWA to depend on as intermediaries between the community and the forum. There is a need for investigation of the background of participants who represent organizations in order to know whether they have the mandate of their community. A self-regulatory method of accountability which according to 
Naidoo [20] is the development of code of conduct through a participatory process to determine the standards expected of NGOs and CBOs in terms of their performance in their communities should therefore be discussed with these groups by DWA. The self-regulatory mechanism will ensure that community organizations voluntarily give themselves the responsibility of reaching out to people in their locality. The lack of interaction between participants from the disadvantaged community and the general public in their community makes these participants less favorable as intermediaries between the community and the organizers of the MCMF. Other existing leadership structures in the community such as resident associations; ward councils and committees should therefore be engaged by the organizers of the MCMF to ensure a broader participation of the public. Smit [21] found councilors to function as a key communication channel between administrators and residents in catchment management forums. Its is argued that councilors should be engaged by organizers of the participation process such as CMFs since they can provide valuable information and contacts at the grassroots level about people who have an interest in water resources management. People with an interest in community welfare such as the parish priest should also be contacted since they are involved most often resolving community issues and will be able to identify community members that have an interest in water resource management [21].

\section{E. Access to Relevant Information and Comprehension}

Critical to a meaningful public participation process is access to information by participants. There is the need for participants to access relevant information on what will be discussed [22], [23]. When participants were asked whether they get access to relevant information in order to participate, the following responses were received:

"Information relating to the catchment i) often given during the meeting but the time give (given) to read the information (understand the information) depends on the type of information and your knowledge background"

"They (DWAF) sometimes give us agenda but sometimes they don't especially when they phone"

"The information (information on what will be discussed at the forum) is given during the presentation and there is not much adequate time to read and understand those (that) information"

From the responses, it could be deduced that relevant information on what will be discussed was not made available to participants before meetings. It is opined that the lack of access to information on what will be discussed affects consensus building among members of an organization or community. The views presented during the forum can therefore be classified as an individual's perspective and not that of the organization or the community as a whole.

Critical to access to relevant information is the ability to comprehend the information. The language, style and format in which information is disseminated in participation process because it can affect participants understanding of the information. The EPA [15] indicated that effort should be made) to ensure that most participants understand the language that is used in the participation process through the avoidance or explanation of unfamiliar terms and jargon.
Repackaging of the technical information so that participants understand and engage in deliberations is therefore vital in a participation process. Participants were therefore asked if they understand the information presented during the MCMF. Below are some of the responses obtained from participants:

"The information they present is always calculation which I don't understand"

"Sometimes they talk about things you don't even understand"

"They just give us statistics that two months ago the water was like this and this time the water is like this sometimes for the whole year. They say we tested this time and the water was so much dirty or clean but we are getting improved but I am not clear because we don't know how the technicians do (arrive at their answers)"

The responses above from these disadvantaged community participants indicate that, the information presented at the forum is often technical. A DWA representative was asked to find out whether participants from the disadvantaged community have sufficient knowledge to understand the technical information presented in the MCMF.

"The technical issues is the heart of the forum I guess in this particular instance because the water quality is a huge issue so the technical issues and its language will be difficult for them

It is argued that any participation process with a technical information whereby participants do not understand amounts to tokenism of participation, since participants are unable to absorb the technical information and contribute. There is therefore a need for the content of technical information to be presented in plain language that will ensure that participants understand what is presented at the forum [22], [23]. The mode of presentation of information in a participation process also affects the information comprehension by participants. This is because individuals learn differently, which requires a variation in the manner in which information is presented to them. The presentation of information in a participation process should therefore be in a form that will be relevant to everyone in a participation process.

Participants were asked how information is presented during meetings. All the participants answered that information is always presented by power point which was confirmed by DWA representative. The problem with power point presentation in a participation process is that it creates a distance between the speaker and the audience, with the audience becoming passive which makes active participation after presentation a difficult task [24] (Scottish Parliament Participation Handbook, 2004). Multiple methods of information presentation such as site visits should be explored. The use of site visits has been found to be useful in a participation process by improving learning and interaction among participants [25]. The use of site visit is reported greatly improves the knowledge of participants since they get the opportunity to see the issues that are discussed, which may not be at their locality. Site visits also improve participants' interaction due to their informal nature therefore bringing participants closer in expressing their grievances to each other [25].

\section{F. Awareness Creation and Notification}

It has been revealed that the medium through which 
participants are notified about a participation process has significant effect on the number and group of stakeholders that attends a forum. It is vital for the organisers of a participation process to ensure that interested and impacted stakeholders are encouraged to participate [7]. When a representative of the organisers of the forum was on how stakeholders' are notified, the response was:

"We try all avenues through posting. Posting is the main one so we rely on the information they provide at the meetings but we found that sometimes being illiterate they just copy someone's box rather than their box. We also rely on e-mailing and in some instances we do fax but other forums we use to phone and in other instances we advertise the forum in the Newspaper (Natal Witness and the Echo)"

Participants were asked whether the medium and timing of notification affects their participation at the forum. Below were some of the responses from the participants:

"When we are at meetings they (DWA) give us the date for the next meeting. The notification is affecting those in the townships because if you don't come to meetings you will not know when the next meeting will come on because they (DWA) don't announce it on the radio and it doesn't come to the news papers"

"They (DWA) use to inform me through the phone. They (DWA) do tell us the objective of the meeting but the problem is the time because sometime the just phone you today (Monday) and the meeting is on Wednesday so there is no time to prepare"

"Sometimes a week to the meeting and sometimes they (DWAF) phone me maybe on Monday and say there is a meeting and I just go. Sometimes if I meet somebody I know the person will tell me there is a meeting they did not tell you and the person will say we must go"

"They (DWA) write to me to attend meetings and also got a call from Cape Town that there will be a workshop so I must be there. They (DWA) sometimes give us agenda but sometimes they don't especially when they phone"

The responses gave an indication that participants were not satisfied with the medium in which they were notified, which could be a major concern to participants of the forum.

\section{CONCLUSION}

The importance of public participation has been established in literature and legislation but attention should be shifted to how best to make it more meaningful to the public. The MCMF is in a unique position to shape and enhance its procedures and mechanisms for the public participation process because it is relatively new compared to others such as Inkomati Catchment Management Agency. The MCMF organizers should therefore not see the physical presence of disadvantaged community stakeholders as a sign of meaningful public participation. Emphasis needs to be placed on the development of skills and capacity of participants to understand and make meaningful contributions, especially participants from the disadvantaged communities. The skill and capacity of the organizers of MCMF also needs to be developed in order to allow them to know how to relate to participants in order to know their level of satisfaction in the participation processes.

\section{REFERENCES}

[1] A. J. Anderson. "Engaging disadvantaged communities: lessons from the Inkomati CMA establishment process," presented at the International workshop on African Water Laws: Plural Legislative Frameworks for Rural Water Management in Africa, Johannesburg, South Africa, 26-28 January, 2005.

[2] D. Du Toit. (May 2005). Preparing people for integrated catchment management: a proposed learning alliance for the implementation of a new legal framework for water management in South Africa reflexive learning in context. [Online]. Available: www.award.org.za/File_uploads/File/Reflexive\%20learningDerick\%2 0DU\%20TOIT\%20FINA L.pdf/

[3] EPA., "Stakeholder involvement evaluation," Environmental Protection Agency (EPA) Project XL Final Report, October, 2000

[4] EPA. "Stakeholder involvement and public participation at the USEPA: lessons learned, barriers, and innovative approaches," Environmental Protection Agency (EPA) Report No EPA-100-R-00-040, January, 2001.

[5] N. Faysse., "An assessment of small-scale users' inclusion in large-scale water user associations of South Africa,” International Water management Institute Research Report 84, 2005

[6] S. Friedman, "Participatory governance and citizen action in post-apartheid South Africa,” International Institute for Labour Studies. Discussion Paper Series DP/164/2006, 2006.

[7] A. Gorgens, G. Pegram, M. Uys, A. G. L. Loots, A. Tanner, and R. Bengu, "Guidelines for catchment management to achieve integrated water resources management in South Africa," Water Research Commission of South Africa Report No KV 108/98, 2008.

[8] A. J. James, "Institutional challenges for water resources management: India and South Africa,” WHIRL Project Working Paper 7, 2003.

[9] F. G. W. Jaspers. "Institutional arrangements for integrated river basin management,” Water Policy, vol. 5, pp. 77-90, 2003.

[10] E. Karar. (2003). Governance in water resources management: progress in South Africa. [Online]. Available: http://www.inbo-news.org/wwf/EKarar_SA.pdf/

[11] A. Kilpiö, J. Laine, and M.L. Markkula. (2005). Process simulation method in training context - analyzing the benefits and challenges. [Online]. Available: http://www.simlab.tkk.fi/events/kilpio.pdf/

[12] M. G. Kweit and R.W. Kweit. "The politics of policy analysis: the role of citizen participation in analytic decision-making," Review of Policy Research, vol. 3, pp. 234-245, 1984.

[13] B. Lankford, C. Sokile, D. Yawson and H. Levite. "The River Basin Game: a water dialogue tool,” IWMI Working Paper.vol.75, 2005.

[14] H. McKay, "The philosophy and practice of Integrated Catchment Management: Implications for Water Resource Management in South Africa. Discussion Document," WRC Report No.TT 81/96, Department of Water Affairs and Forestry (DWAF), Water Research Commission, Pretoria, South Africa, 1996.

[15] K. Naidoo. (2003). Civil society accountability: who guards the guardians? [Online]. Available: http://www. civicus.org/new/media/NGO\%20Accountability.doc/

[16] National Environmental Management Act. (1998). South Africa Act No. 107 of $1998 . \quad$ [Online]. Available: http:// www.info.gov.za/gazette/acts/1998/a107-98.pdf/

[17] J. Petts, "Evaluating the effectiveness of deliberative processes: waste management case-studies," in Journal of Environmental Planning and Management, vol. 44 no. 2, pp. 207-226, April, 2001.

[18] Republic of South Africa, the Water Services Act. Act No. 108 of 1997. Government Gazette. RSA

[19] Republic of South Africa, the National Water Act. Act No. 36 of 1998. Government Gazette. RSA

[20] Scottish Parliament Participation Handbook. (2004). Participation Handbook Toolkit. [Online]. Available: http://www.scottish.parliament.uk/vli/participationHandbook/Particip ation_Handbook_6th_August_2004.

[21] W. R. D. Sewell and J. T. Coppock. "A perspective on public participation in planning," in Public Participation in Planning, W.R.D. Sewell and J. T. Coppock, Eds. London: John Wiley \& Sons Ltd, 1977.

[22] T. Smit. (July 2003). Catchment management forums in the Eastern Cape Province of South Africa. [Online]. Available: http://www.waterforfood.nl/msp/content/uk/southAfrica/articles/Foru m\%20report\%20Tim\%20Smit.pdf

[23] L. Solitare, "Prerequisite Conditions for Meaningful Participation in Brownfields Development.," Journal of Environmental Planning and Management, vol. 5, no. 6, pp. 917-935, August, 2005.

[24] L. Soneryd, "Public involvement in the planning process: EIA and lessons from the Örebro airport extension, Sweden,” Environmental Science and Policy, vol. 7, pp. 59-68, February, 2004. 
[25] UNECD. Environment and sustainability. United Nations Environment Conference on Development

[26] S. Friedman, "Participatory governance and citizen action in post-apartheid South Africa," International Institute for Labour Studies. Discussion Paper Series DP/164/2006, 2006

[27] A. Gorgens, G. Pegram, M. Uys, A. G. L. Loots., A. Tanner, and R. Bengu, "Guidelines for catchment management to achieve integrated water resources management in South Africa," Water Research Commission of South Africa Report No KV 108/98, 2008.

[28] H. McKay. The philosophy and practice of Integrated Catchment Management: Implications for Water Resource Management in South Africa. Discussion Document. WRC Report No.TT 81/96, Department of Water Affairs and Forestry (DWAF), Water Research Commission, Pretoria, South Africa, 1996.

[29] A. J. James, "Institutional challenges for water resources management: India and South Africa," WHIRL Project Working Paper 7, 2003.

[30] E. Karar. (2003). Governance in water resources management: progress in South Africa. [Online]. Available: http://www.inbo-news.org/wwf/EKarar_SA.pdf/

[31] A. J. Anderson, "Engaging disadvantaged communities: lessons from the Inkomati CMA establishment process," presented at the International workshop on African Water Laws: Plural Legislative Frameworks for Rural Water Management in Africa, Johannesburg, South Africa, 26-28 January, 2005.

[32] N. Faysse, "An assessment of small-scale users' inclusion in large-scale water user associations of South Africa,” International Water management Institute Research Report 84, 2005.

[33] Republic of South Africa, the Water Services Act. Act No. 108 of 1997, Government Gazette. RSA.

[34] Republic of South Africa, the National Water Act. Act No. 36 of 1998. Government Gazette, RSA.

[35] D. Du Toit. (May 2005). Preparing people for integrated catchment management: a proposed learning alliance for the implementation of a new legal framework for water management in South Africa reflexive learning in context. [Online]. Available: http://www.award.org.za/File_uploads/File/Reflexive\%20learningDer ick\%20DU\%20TOIT\%20FINA L.pdf/

[36] Rivers-More and Hay L. Soneryd, "Public involvement in the planning process: EIA and lessons from the Örebro airport extension, Sweden," Environmental Science and Policy, vol. 7, pp. 59-68, February, 2004.
[37] EPA, “Stakeholder involvement evaluation,” Environmental Protection Agency (EPA) Project XL Final Report, October, 2000.

[38] EPA, "Stakeholder involvement and public participation at the USEPA: lessons learned, barriers, and innovative approaches," Environmental Protection Agency (EPA) Report No EPA-100-R-00-040, January, 2001.

[39] M. G. Kweit and R. W. Kweit, "The politics of policy analysis: the role of citizen participation in analytic decision-making," Review of Policy Research, vol. 3, pp. 234-245, 1984.

[40] F. Khan. (2007). Public Participation and Environmental Decision-making in South Africa - The Frankdale Environmental Health Project. [Online]. Available: http://www.egs.uct.ac.za/sagj/Khan80(2).html - 54k/

[41] L. B. Kessler, "Stakeholder participation: a synthesis of current literature," Prepared by the National Marine Protected Areas Center in cooperation with the National Oceanic and Atmospheric Administration Coastal Services Center, 2004.

[42] L. Solitare, "Prerequisite Conditions for Meaningful Participation in Brownfields Development,” .Journal of Environmental Planning and Management, vol. 5 no. 6, pp. 917-935, August, 2005.

[43] K. Naidoo. (2003). Civil society accountability: who guards the guardians? [Online]. Available: http://www. civicus.org/new/media/NGO\%20Accountability.doc/

[44] T. Smit. (July 2003). Catchment management forums in the Eastern Cape Province of South Africa. [Online]. Available: http://www.waterforfood.nl/msp/content/uk/southAfrica/articles/Foru m\%20report\%20Tim\%20Smit.pdf

[45] A. Kilpiö, J. Laine, and M. L. Markkula.(2005). Process simulation method in training context - analyzing the benefits and challenges. [Online]. Available: http://www.simlab.tkk.fi/events/kilpio.pdf/

[46] B. Lankford, C. Sokile, D. Yawson, and H. Levite, "The River Basin Game: a water dialogue tool,” IWMI Working Paper, vol.75, 2005.

[47] Scottish Parliament Participation Handbook. (2004). Participation Handbook Toolkit [Online]. Available: http://www.scottish.parliament.uk/vli/participationHandbook/Particip ation_Handbook_6th_August_2004.

[48] J. Petts, "Evaluating the effectiveness of deliberative processes: waste management case-studies," Journal of Environmental Planning and Management, vol. 44, no. 2, pp. 207-226, April, 2001. 